\title{
ASPECTS OF GULF COAST LATE NEOGENE SEQUENCE STRATIGRAPHY
}

\author{
SHAFFER*, Bernard L.; PACHT, Jory A.; BOWEN, Bruce E., TGS-CALIBRE Interpretations \\ Co., 333 Clay, Suite 3900, Houston, TX 77002.
}

With its vast well and seismic data base, coupled with expanded sedimentary and biostratigraphic cycles that apparently were driven by glacial eustacy, the Gulf Coast offshore region provides a unique opportunity to develop and test sequence models. Virtually every major oil company and a number of academic institutions are currently engaged in some form of sequence analysis.

Regional studies incorporating biostratigraphic analyses of more than 120 wells integrated with a seismic grid exceeding 24,000 line smiles, have shown the Gulf Coast to be an unstable prograding margin, and that characteristic seismic criteria developed for stable progradational margin models do not always apply. Biostratigraphic approaches consistent with the procedures and objectives of sequence analysis thus play a preeminent role in providing a chronostratigraphic framework, and in utilizing biotic patterns to aid in the delineation of systems tracts.

For the pre- Wisconsin Plio-Pleistocene, 15 biostratigraphically and seismically resolvable and regionally mappable sequences are documented. Those for the past one million years approximate 100,000 year cycles. All of the sequences are calibrated by highest occurrence datums (HOD) which almost invariably occur within condensed sections developed either during maximum flooding events or on lowstand slope fans. This association with condensed sections begs the question whether or not these HOD are true extinctions, and whether or not sediment accumulation rates, or similar techniques, derived from them, can reliably be used to establish the position and absolute age of sequence bounding unconformities.

Seismic and well data suggest that sequence bounding surfaces in this province are usually subtle, and that the hiatus they may represent is, except in extreme cases, beyond the resolution of the biostratigraphic framework. Sequence boundary placement can be routinely interpreted through integration of biostratigraphic data, including condensed sections, wireline log patterns, and seismic character. In slope paleo-environments, condensed sections commonly are temporally equivalent to both the transgressive and highstand systems tracts on the shelf, and their upper surface may coincide with the sequence boundary. In paleo-shelf settings, condensed sections frequently are restricted to the transgressive systems tract, and their contained HOD may be suppressed by succeeding highstand deposits. In such cases, sequence boundaries are best placed by wireline log and seismic criteria.

Pitfalls and limitations to the proposed biostratigraphic approach to sequence stratigraphy are discussed and illustrated. 